\title{
Failure Analysis in Passenger Bogies from the Railway System of the Republic of Bulgaria
}

\author{
Vanio Ralev ${ }^{1 *}$, Dobrinka Atmadzhova ${ }^{1}$ \\ ${ }^{1}$ Machinery and Construction Technologies in Transport/Transport Equipment, Todor Kableshkov University ofTransport, \\ Sofia (Bulgaria) \\ This paper is based on a review of a study of damage to passenger bogies on railway vehicles. The results of the \\ research of the reliability of the passenger bogies from the park of the Bulgarian State Railways (BDZ) are analyzed. The \\ constructions of passenger bogies type swing in the operation of the Republic of Bulgaria are presented - YT72, Görlitz V \\ and GP200. The most common faults of the passenger bogies are indicated. The general failures, the probable causes of \\ failures and the ways to minimize them have been successfully identified.
}

Keywords: Railway vehicles, passenger cars, bogies.

\section{INTRODUCTION}

All modern passenger wagons are with bogies. Passenger wagons are subject to greater requirements in terms of smoothness, the size of the accelerations of the body car and the dynamic forces, and for movement at much higher speeds $[1,2]$. This imposes a number of requirements on the construction of passenger wagons, namely:

a) a small total mass of the bogies and especially of the unsprang parts;

b) providing a large static sag (especially in therange of 200-300 mm) of spring suspension in two degrees;

c) realization of an elastic connection in the transverse direction between the basket (respectively the spring beam) and the bogie frame by means of a rocking device in the central spring stage, working on the pendulum principle, or by using horizontal transverse deformation of the central springs;

d) an effective system for damping all types of oscillations;

e) the distance between the spring sets, measured transversely to the wagon, shall be as large as possible and the side bearer on the bogies shall lie closer to the plane passing through the axles of the wheels in order to increase the lateral stability and reduce the intensity of the lateral oscillations of the carbody;

f) the braking system to be with high efficiency, etc.

\section{THE CONSTRUCTION TYPE SWING BOGIE}

The first Bulgarian passenger bogie, produced in our country for the VKAZH-57 wagons, is similar to the carriages of the Görlitz IV family (Germany). The second Bulgarian construction used in the non-compartment and part of the compartment cars manufactured in our country after 1964 is the T-65 bogie.

Frequent damages in primary suspension require structural changes, after which the bogie receives the designation T 65-2. On its basis in 1972 the bogie YT-72 was created [3].

The Görlitz-V bogie is used in most of the wagons imported from Germany, and the imported couchette wagons have GP 200 bogies.
The object of this article are bogies type YT-72, Görlitz-V/Va/DVJ and GP 200.

\subsection{Bogie YT-72 and YT-72 A}

The bogie YT-72 (fig.1) is intended for wagons type B4-68 and 70 .

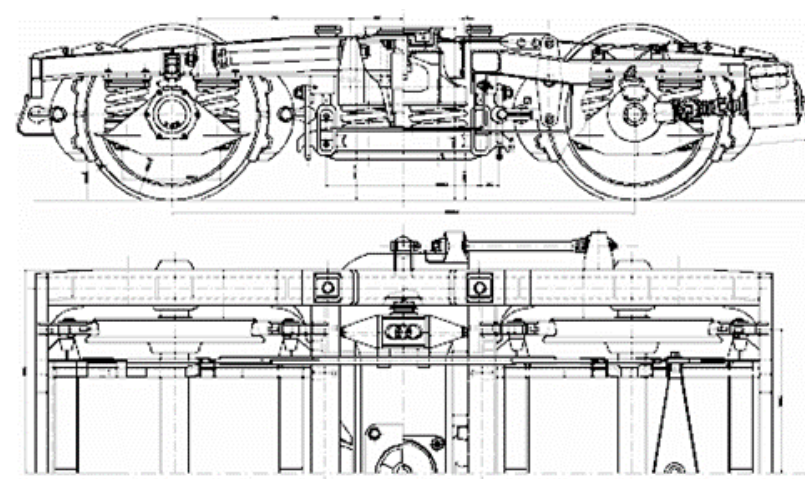

Figure1. General view of the bogie type YT-72.

The base of the bogie is $2.5 \mathrm{~m}$, the wheel axles in the rolling circle for the bogie YT-72 are $1000 \mathrm{~mm}$, and for the bogie YT-72A are $920 \mathrm{~mm}$. Design speed $-160 \mathrm{~km} / \mathrm{h}$.

The frame is a welded construction, closed type, consisting of two side longitudinal beams, front beams, cross beams and inner beams.

The spring suspension is made of springs.

The axle boxes are spindle driven. The primary suspension consists of two sets of double coil springs and a friction vibration damper, consisting of a conical sleeve and 6 conical segments pressed by the inner axle spring.

The secondary spring suspension consists of 4 sets double coil springs, two vertical hydraulic dampers with a stroke of $150 \mathrm{~mm}$, mounted externally and two transverse horizontal hydraulic dampers with a stroke of $100 \mathrm{~mm}$, mounted internally between the bolster and the internal crossbeams of the frame. The transverse elastic mobility between the car body, respectively the bolster of the bogie and its frame, is realized by a swing device in the secondary suspension (as in the bogie T-65). The bogie has two linkers for longitudinal guidance of the spring beam and a generator for lighting 
The vertical load from the car body is transmitted to the bogie only by the side bearers. The central pivot is a traditional type (cylindrical flat), but its upper part is raised by $10 \mathrm{~mm}$, so it transmits only horizontal loads.

\subsection{Bogie type Görlitz V}

The Görlitz V bogie [3] is a modern construction (Fig. 2) with a two-stage suspension of cylindrical coil springs only.

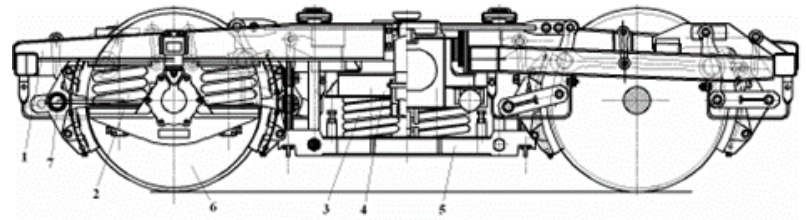

Figure 2. Bogie Görlitz V 1-frame; 2-primary suspension; 3-secondary suspension; 4-bolster; 5-spring beam; 6wheelset; 7- braking system.

The secondary suspension is a swing, made of four sets of coil springs lying on two beams, which are suspended in a pendulum in the frame of the bogie. The spring beam is suspended to the bogie frame by means of balancing bolts (swing supports). The adjustment of the distance "buffers-head rail" is carried out by means of a balancing nut on the frame of the bogie and a screw thread of the balancing bolts. The movement of the swing in space amounts to $25 \mathrm{~mm}$ in the transverse direction and $5 \mathrm{~mm}$ in the longitudinal direction. The transverse and longitudinal clearances of the swing are limited by metal- rubber supports. The damping is in the secondary suspension and is carried out by two vertical and two horizontal dampers.

The primary suspension consists of two coil springs located on both sides of the axle on its wings. The axle wings are guided by spindles and bushings located between them.

The bogie frame consists of two longitudinal beams, two transverse beams forming the cradle space and two front beams.

The car body rests on the side bearer by a centre pivot of flat type, and the lateral support of the car body is done by height-adjustable hinged sliders. There is a small gap between the bogie sliders and the car body, so that the vertical and horizontal loads from the car body on the frame are transmitted through the canter pivot, and only the additional vertical loads from the centrifugal and wind force of the car body are transmitted through the sliders.

The base of the bogie is $2.5 \mathrm{~m}$. Mass of the bogie $6103 \mathrm{~kg}$.

\subsection{Bogie type Görlitz Va/DVJ}

This bogie (Fig. 3) has been reconstructed in order to provide good ride quality, noise reduction by installing additional rubber elements, and also by installing disc brakes to achieve a better braking effect. This bogie (Fig. 3) has been reconstructed in order to provide good ride quality, noise reduction by installing additional rubber elements, and also by installing disc brakes to achieve a better braking effect. This bogie (Fig. 3) has been reconstructed in order to provide good ride quality, noise reduction by installing additional rubber elements, and also by installing disc brakes to achieve a better braking effect.

The new bogies are equipped with a disc brake system, modified spring suspension, and modified bearing, additional rubber elements for sound insulation, grounding of the axle ends and at the same time electronic traction protection.

The guide of the axle box has been changed using a new development of DVJ, namely tight-elastic guide of the axle boxes.

The guide elements (spindles) have retained their old dimensions and are mounted on the machined surfaces of the bogie frame.

The rubber ring, ensuring the elasticity of the axle box connection, is placed in a tubular construction.
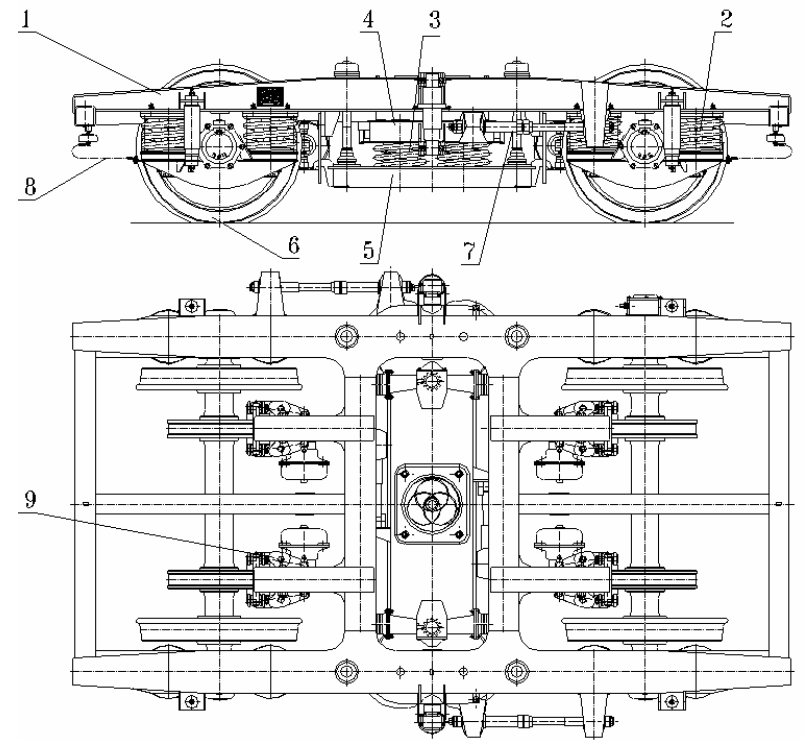

Figure 3. General view of the Görlitz Va/DVJ bogie 1frame; 2- primary suspension; 3- secondary suspension; 4- bolster; 5-spring beam; 6- wheelset; 7-linker; 8earthing device; 9- braking system.

The secondary suspension (Fig. 4) is made of four sets of cylindrical coil springs that lie on newly manufactured spring beams (bathtubs). The double spring set also has a rubber pad, which in case of overload or larger dynamic thrusts, is like a third spring element and helps to absorb the load.

The damping is performed with two hydraulic dampers in vertical and horizontal direction, the over sprung beam is connected to the bogie frame. The damping characteristic is progressive.

The connection between the bolster and the central bolt beam of the wagon is made by means of a central pivot of flat type. Between the upper and lower part of the camp there is a so-called "Central bolt".

When tilted transversely, the side bearers stabilize the car body. The side bearers are adjustable and can be adjusted without play. 


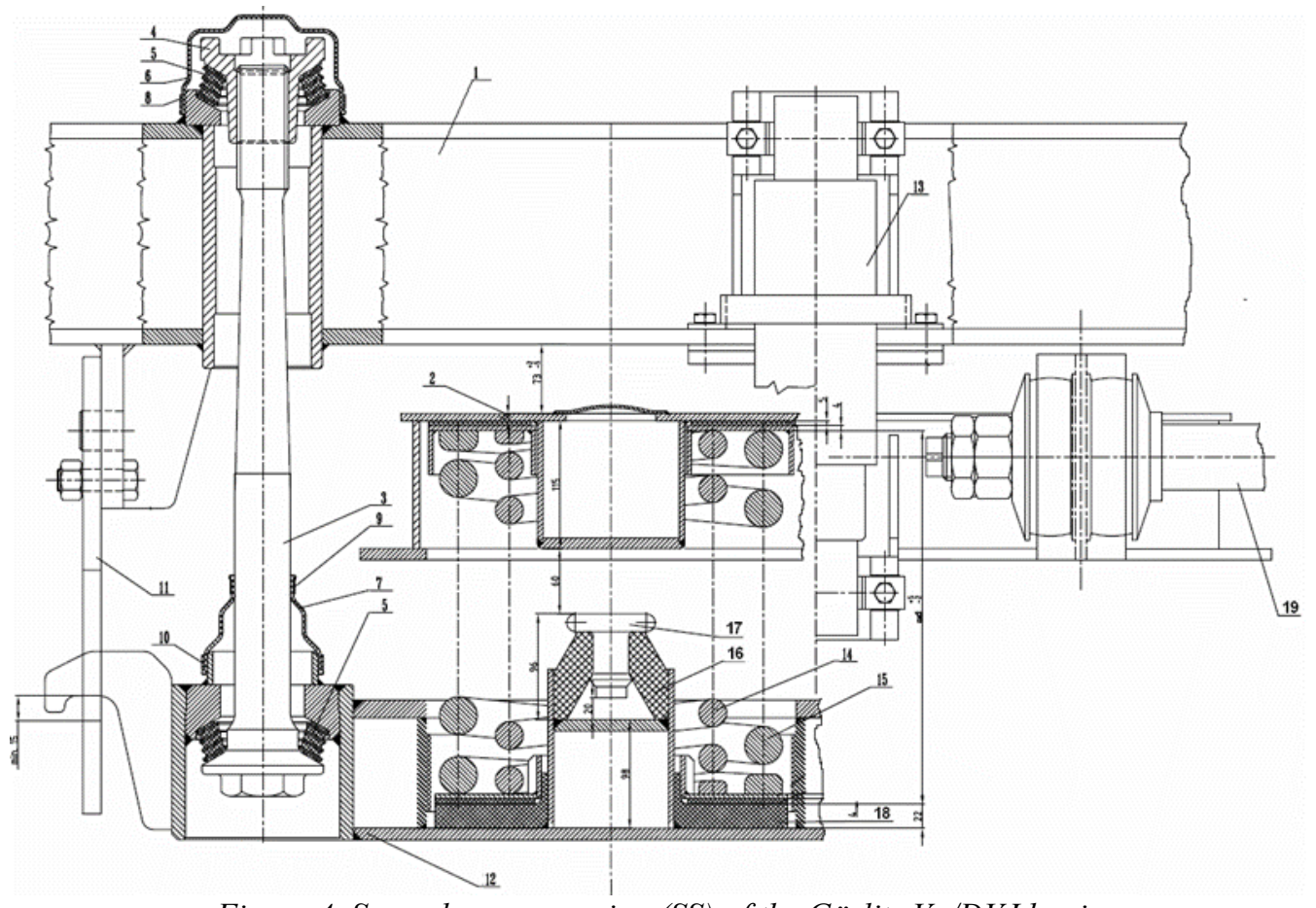

Figure 4. Secondary suspension (SS) of the Görlitz Va/DVJ bogie

1-frame; 2- bolster; 3- balancing bolt; 4- nut; 5 - rubber-metal package; 6 - cap; 7 - casing; 8, 9, 10 - washer; 11 insurer; 12 - spring beam; 13 - damper; 14 - internal spring from SS; 15 - outer spring from the SS; 16-bumper rubber; 17 - beater; 18 - rubber support; 19 - linker.

The braking system is disc and two brake kits (disc + cylinder) are mounted on each axle.

\subsection{Bogie type GP200}

The GP 200 bogie (Fig. 5) was developed by the VÚKV Institute for Railway Vehicle Research as an international project developed by VÚKV together with Vagonka in Görlitz, Germany, with the name GP 200, meaning the maximum possible design speed using an electromagnetic rail brake.

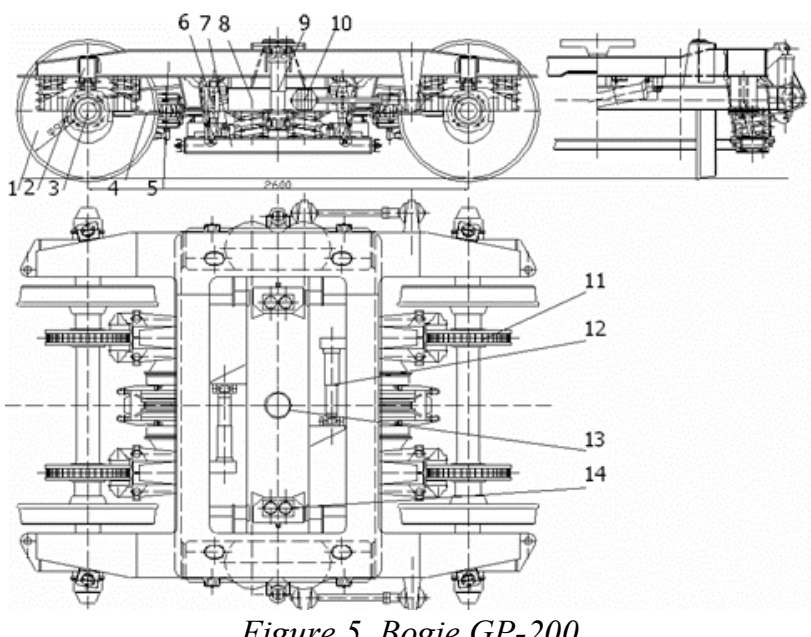

Figure 5. Bogie GP-200

1-wheelsets; 2-friction damper; 3-axle box; 4-guides; 5frame; 6-swing pendants; 7-spring beam; 8-bolster; 9vertical hydraulic damper; 10-linker; 11-sided disc; $12-$ horizontal hydraulic damper; 13 - center pivot; 14 - slide bearer.

The GP 200 bogies are two-axle with a two-stage spring cradle suspension for light railway vehicles. Base
$2600 \mathrm{~mm}$. Carriage weight $-5400 \div 6035 \mathrm{~kg}$. Year of production 1984 and 1990 .

The bogie frame is a welded construction.

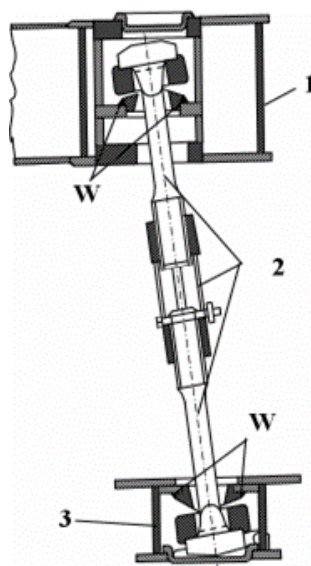

Figure 6. Inclined outwards at an angle of about $10^{\circ}$ swing pendants

1 - bogie frame; 2- swing pendants (upper stabilizer, connecting nut, lower stabilizer); 3- spring beam (bathtub); $W$-welding.

The frame consists of two longitudinal and two transverse elements.

The secondary suspension is swung by means of swing pendants inclined outwards at an angle of about $10^{\circ}$ (Fig. 6).

The guide axle box is guided by an elastic fiberglass connection, fixedly connected to the wing of the axle box body by a bolted connection, and on the other side to the bracket of the bogie frame (Fig. 7). The detachable axle box body allows disassembly of the axles without disassembly of the axle spring suspension. The axle box body consists of three parts. 


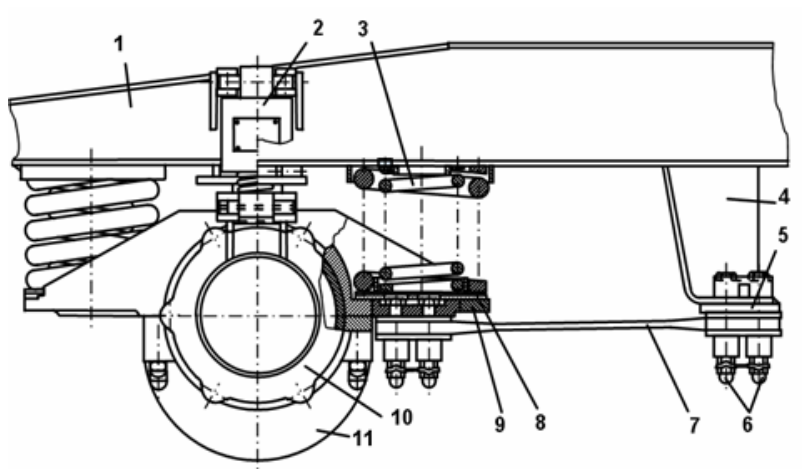

Figure 7. Primary suspension

1-frame; 2-friction damper; 3-springs from the primary suspension; 4-support; 5-slot connection; 6-bolt

connection; 7- elastic fiberglass flat connection; 8-pad; 9axle body-upper part; 10- axle body - middle part; 11axle body - lower part.

Bearings, safety and labyrinth rings are mounted in the cylindrical sleeve of the axle box body. The axle box cover is mounted to the cylindrical part

The bolster has a closed section made of steel sheets. The center pivot, the side bearer, the baffles and hinges for horizontal and vertical dampers and the linker connection are mounted on the over sprung beam.

\section{FAILURE IN PASSENGER BOGIES TYPE SWING OF THE RAILWAY SYSTEM OF THE REPUBLIC OF BULGARIA}

The importance of the problems related to the strength condition and especially the durability of the bogies of the passenger wagons can be judged by the fact that they are decisive for the safety of the movement. Indeed, all failures of passenger wagons of a strong nature, ie. all destruction leads directly to severe accidents and catastrophes related to the lives of passengers.

Of course, in the framework of the present work not all cases of failures can be found, but only those of them will be affected, which are related to mass defects and are mainly due to design deficiencies and mass deviations from technological requirements [4]. Wheelset and braking systems failures will not be treated because they are subject to separate regulations and special attention, although they can be said to have problems [5, 6, 7].

We will note in advance that due to the dynamic nature of the loads on the passenger wagons and due to the presence of a certain level of technical literacy of the staff in the railways, the destruction is in all cases caused by fatigue of the material, ie. from cyclic rather than one-time loads. This assessment for the specific cases is confirmed by the characteristic features - lack of neck (thinning of the section) at the site of destruction and the presence of visible to the naked eye different areas of fracture, characteristic of different stages of crack development. It should be noted that these stages are not short-lived and it is good that it is so, because there is a possibility to detect the crack before the actual loss of performance, ie. before the demolition itself took place, characterized by the division of the part into two parts. Ways and means to detect cracks is the subject of another topic.

Unfortunately, fatigue damage is almost always widespread [4]; they are characteristic and do not appear as single cases, but for whole series and production batches.
Because this type of destruction requires a large number of load cycles (hundreds of thousands and millions

- usually up to 10 million for steel), which cannot be obtained either in factory tests and test trips, or in institute tests, but accumulate over time. of a relatively long period of operation.

It can be said that such mass damages did not occur after the institute tests, which actually started from 1964 to 1965, were introduced for serial productions after 1970 , because in these tests, also called "determinants", in addition to the dynamic-running indicators, also the strength properties, the stresses that precisely cause the cracks.

However, even with this approach (by performing definitive tests) there is no complete guarantee for cracks and damage.

Here will be considered only those of the elements and units of the bogie that require close attention.

A) In the first place - are the object of close attention - The joints between the sides and crossbeams. Very low stresses were obtained in these places during the static bench tests, according to UIC 515 [8], but during the train tests in the conditions of movement in curves the stresses are significantly higher. From the analysis of the records and from the additional stationary tests performed by simulating the loads in curves, it was found that these high stresses are due to the pair of longitudinal shoulder forces caused by the longitudinal components of the creep forces when entering a curve. Due to the high responsibility of this unit in the subsequent strength vibration tests of fatigue [9] an additional cyclic load was realized (which is not prescribed by UIS slip 515 [8]), trying to cause horizontal oblique deformation of the frame, turning it from a rectangle into rhomboid (seen in plan!). In addition, the requirements of the Transport Research Institute (NITIZHT) include the requirement for mandatory defectoscopy of the welds in this unit. Unfortunately, however, data were later found showing that this unit was not implemented for all bogies of the required quality. This is the main reason for placing this unit among those that should be the subject of close attention during operation and repair.

B) Secondly - are the object of attention to the brackets (ears), through which the longitudinal linkers are connected to the bolder and the sides of the bogie frame, in and around the joints. To reduce the high stresses resulting from different train conditions, it is recommended to increase the radius of curvature at the base of the brackets and improve the quality of the welds connecting the latter to the bolster or the side. In addition, there are recommendations regarding the linker rubber "hinges", because the stresses in the specified places strongly depend on the serviceability of these "hinges" or on the extent to which they act as such, ie. without generating a bending moment of tension or with the lowest possible value of the same. This factor depends on the quality of the tire, the degree of its tension, etc., which does not exclude striking faults associated with leaning "hard" and locking.

Therefore, along with the checks for cracks in the indicated places of the linker consoles, it is necessary in case of factory repair (and if possible, in case of depot) to check the force for the necessary vertical and horizontal deviation of the lantern at one end, free from metal package, 
provided that the other end is connected to the corresponding metal package.

C) Thirdly, cracks can be expected under certain conditions in the lower sheet of the spring beam around the places near the edges of the brackets, perceiving the transverse forces as reactions of the elastic bumpers. In these places cracks occur in bench fatigue tests at 6 million cycles, in connection with which recommendations are given with welding of external or internal ribs. After the implementation of the recommendations, the structures are tested on a multi-cycle load and they can withstand the prescribed loads according to EN 13749 [10] and EN 14363 [11], calculated with a large reserve for the depreciation period of the wagons.

\section{NECESSARY CONDITIONS FOR PUTTING INTO SERVICE OF BASIC ELEMENTS OF PASSENGER BOGIES}

When putting railway carriages into operation according to the European normative documents, obligatory stages are:

- Development of constructive and technological documentation;

- Conducting strength-strain analysis;

- Testing of a prototype.

The normative documents of the European Union and the UIC allow the commissioning to take place only on the basis of strength-strain analysis. The necessary conditions for this are:

- The manufacturer has received a bogie certificate with similar design, technological and operational characteristics;

- To perform the full volume of theoretical research with verified computational and simulation models.

The normative documents related to the testing and theoretical examination of railway bogies (including the study of fatigue of the material in the welds in the metal structure) are EN 15827: 2011 [9], EN 13749: 2011 [10], UIC 510- 3 [13], UIC 615-4 [14] UIC 515-4 [15], TSI [16], ERRI B 12 / RP 17 [17], ERRI B 12 / RP 60 [18], EN 12663-1: 2010 [19], DVS 1612: 2014 [20] and Eurocode 3 [21]. Their analysis shows that the forces of loading, the places of their application, the combinations under the different regimes (groups of loads) are clearly and unambiguously defined [10].

The analysis of the normative documents regarding the study of the fatigue of the material in the area of the welds in theoretical and experimental way shows some differences. The reason for this is that the theoretical assessment is performed by quantitative indicators (allowable stresses), and in the experimental - by qualitative (presence or absence of cracks).

The German national welding standard DVS 1612: 2014 [20] is preferred by most European manufacturers of railway equipment and complex machine-building products due to the very good results regarding the reliability of the welds. The standard is based on curves Moore-KommersJasper (MKJ) diagram.

Depending on the type of welded structure, the type of weld, the control technology and the type of applied load, a diagram is selected to determine the allowable stresses. In the general case for the study of complex machine-building products under complex loading, the assessment is performed by four consecutive criteria, three by components and one complex [21, 22, 23, 24], formulas:

$$
\begin{gathered}
\frac{\sigma_{I I}}{\sigma_{\text {II lim }}} \leq 1 ; \frac{\sigma_{\perp}}{\sigma_{\perp l i m}} \leq 1 ; \frac{\tau}{\tau_{\text {lim }}} \leq 1 ; \\
\left(\frac{\sigma_{\text {II }}}{\sigma_{\text {II lim }}}\right)^{2}+\left(\frac{\sigma_{\perp}}{\sigma_{\perp l i m}}\right)^{2}-\frac{\sigma_{I I} \sigma_{\perp}}{\sigma_{\text {II lim }} \sigma_{\perp \text { lim }}}+\left(\frac{\tau}{\tau_{\text {lim }}}\right)^{2} \leq 1,1
\end{gathered}
$$

where $\sigma_{\|}$are normal stresses longitudinally of the weld; $\sigma_{\perp}$ - normal stresses transverse to the weld; $\tau$ - tangential stresses longitudinally at weld; $\sigma_{\| l i m}$ - normal allowable stress along the seam; $\sigma_{\perp \text { lim }}$ - normal allowable stresses; $\tau_{\text {lim }}$ - tangential allowable stresses longitudinally at the weld.

The allowable stresses $\sigma_{\text {lim }}\left(R_{-} \sigma\right)$ are a function of the cyclic load asymmetry coefficient, which is calculated according to the formula:

$$
\sigma_{\text {lim }}\left(R_{\sigma}\right)=150 \cdot\left(1,04^{-x}\right)\left[\frac{2 \cdot\left(1-0,3 R_{\sigma}\right)}{1,3 \cdot\left(1-R_{\sigma}\right)}\right]
$$

where $x$ is the exponent depending on the selected curve corresponding to the respective weld and load.

\section{TESTING OF FATIGUE STRENGTH OF PSSENGER BOGIES}

According to the requirements of the International Railway Union - UIC 510 [13] and UIC 515-4 [15] bench tests of wagon bogies are of two types and are conducted in two stages in the following sequence, usually on the same sample:

- first stage - static (for static strength);

- second stage - dynamic (for fatigue strength).

In addition, there are the conditions: a) dynamic bench tests (which are more lengthy and expensive) to be conducted if the respective sample (construction) has successfully "passed" the static tests at the 1st stage; (b) bench tests of wagon bogies must be carried out on: new or modified structures; new or changed technologies; material replacement; new company-manufacturer and new place (workshop, factory) for production.

\subsection{Dynamic fatigue strength tests}

The loads (forces) on the test bogie acting in the vertical transverse plain through the central bearing are first grouped [3, 25] (see Fig. 8) in:

- system of vertical forces Fz1 and Fz2. Applied on the right and the left side beams in the plane of the central bearing;

- a system of horizontal forces $\pm \mathrm{F}_{\mathrm{y} 1}$ and $\pm \mathrm{F}_{\mathrm{y} 2}$, also applied to the right and left side beams in the plane of the center bearing, usually assuming: $F_{\mathrm{y} 1}=\mathrm{F}_{\mathrm{y} 2}=\mathrm{F}_{\mathrm{y}}$.

The vertical forces $F_{z 1}$ and $F_{z 2}$ are different from each other in time $t$, and are considered to be composed of 3 components - one constant and two periodically changing (see Fig. 12), as follows:

- vertical static component $\mathrm{F}_{\mathrm{zS}}=$ const;

- vertical quasi-static components $\pm \mathrm{F}_{\mathrm{zq}}$;

- vertical dynamic component $\pm \mathrm{F}_{z \mathrm{~d}}$.

It is customary for the right and left curves to have the same parameters and to alternate without straight lines. The period $\mathrm{T}_{\mathrm{q}}$ of the periodic function has thus obtained (component $\mathrm{F}_{\mathrm{zq}}$ ) in the tests must be significantly longer than period $\mathrm{T}_{\mathrm{dq}}$ of the dynamic component (according to UIC-510 and 515). 

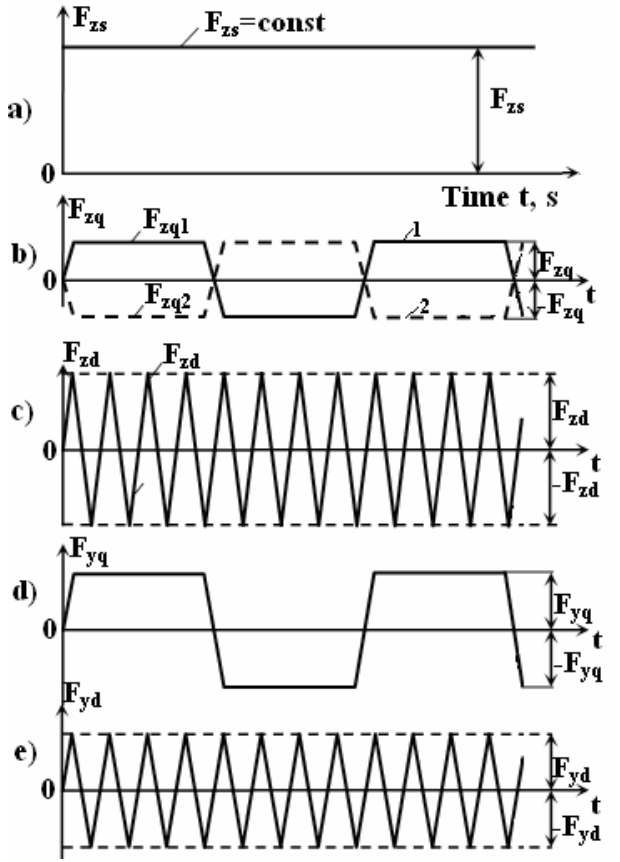

Figure 8. Loads applied to the side beams of the passenger bogie frame [4, 22] according to code. UIC - 515 [13]: $a, b, c$-vertical: static $F_{z s}$, quasi-static $F_{z q}$ and dynamic

$F_{z d} ; d, e$-horizontal-transverse; quasi-static $F_{y q}$ and dynamic $F_{y d}$.

1- right side beam; 2- left side beam.

The horizontal forces $\mathrm{Fu}$ of each side beam, which are equal in size and direction, are composed of two periodically changing components over time (see Fig. 8, d, e), as follows:

horizontal quasi-static component $\pm \mathrm{F}_{\mathrm{yq}}$;

horizontal dynamic component $\pm \mathrm{F}_{\mathrm{yd}}$.

With the mandatory UIC-510 and 515 phase correspondences between $\mathrm{F}_{\mathrm{zq}}$ and $\mathrm{F}_{\mathrm{yq}}$ and between $\mathrm{F}_{\mathrm{zd}}$ and $\mathrm{F}_{\mathrm{yd}}$, the aim is clearly to test the most unfavorable operational combinations that can be obtained, albeit for a short time.

To determine the value of the vertical static component $\mathrm{F}_{\mathrm{zs}}(\mathrm{t})=$ const and the amplitude values of the periodically changing components $\mathrm{F}_{\mathrm{zq}}, \mathrm{F}_{\mathrm{zd}}, \mathrm{F}_{\mathrm{yq}}$ and $\mathrm{F}_{\mathrm{yd}}$, defined above, UIC-510 and 515, respectively for bogies of freight and passenger wagons - are suitable in different ways, although there is an analogy between them.

According to this approach, the values of the 5 load components in question in the bench tests are determined as follows:

1) The vertical static component $\mathrm{F}_{\mathrm{zs}}$

$$
F_{Z S}=1 / 4 \cdot\left(m_{V O N}+1,2 \cdot m_{C N}-2 m^{+}\right) \cdot g
$$

where: $m_{V O N}$ is the curb weight of the wagon; $m_{C N}-$ payload; $m^{+}$- bogie mass.

2) The vertical quasistatic components $F_{z q}$

$$
F_{z q}= \pm \alpha \cdot F_{z s}
$$

where: $\alpha$ is the coefficient for the influence of road condition ( $\alpha=0,10$ for normal and $\alpha=0,15$ for bad).

3) The vertical dynamic component $\mathrm{F}_{z \mathrm{~d}}$

$$
F_{z d}= \pm \beta \cdot F_{z s}
$$

where: $\beta$ is the coefficient of dynamism $(\beta=0,2$ for normal road condition; $\beta=0,3$ for bad road)
4) The horizontal quasistatic component $F_{y q}$ and the horizontal dynamic component $\mathrm{F}_{\mathrm{yd}}$ to each side beam are determined by formula

$$
F_{y q}=F_{y d}= \pm 0,125\left(F_{z s}+0,5 m^{+} \cdot g\right) \text {. }
$$

The normal duration of fatigue tests is $6.10^{6}$ pcs. cycles, which is stage I. At the end of the first stage, at $6.10^{6}$ pcs. cycles the elements of the bogie structure (bogie frame) must not have cracks, even in the embryo. The stage ends with an intermediate qualitative and quantitative assessment. Quality assessment is mandatory and requires full control of welds. The criterion is the absence of cracks. Quantitative evaluation is most often performed with Goodman-Smith diagrams [4]. It allows exceeding the stresses above the normalized in a limited number of controlled points. The condition of these areas is closely monitored in the next two stages. This is the condition for putting the bogie into regular production. However, in order to evaluate the construction and with a view to greater safety, the tests are continued in stage II, which contains $2.10^{6}$ pieces. cycles with $20 \%$ increased dynamic and quasi-static loads $\mathrm{F}_{\mathrm{zq}}, \mathrm{F}_{\mathrm{zd}}, \mathrm{F}_{\mathrm{yq}}$ and $\mathrm{F}_{\mathrm{yd}}$ while maintaining the vertical static load $\mathrm{F}_{\mathrm{zs}}$. In order to give a positive assessment of stage II, namely that the structure is "durable", it should not have cracks, but germs of cracks up to $2-3 \mathrm{~mm}$ are allowed. Provided that they have successfully passed the tests of stage II, another continuation is undertaken - stage III $-2.10^{6}$ pcs. cycles and by $40 \%$ increase compared to stage I quasi-static and dynamic loads while maintaining the static. The condition for successfully passing stage III is the same as for the previous one.

During the tests, the condition of the tested structure is constantly monitored in parallel with the operation of the stand, as in the event of unusual noises, shocks (crashes), deformations, etc. the work is stopped to clarify the condition. It is recommended that work be interrupted every 1 million cycles to perform a basic inspection - primarily for cracks. There are international requirements for documenting test regimes and results obtained.

\subsection{Static bench tests (static strength tests)}

The loads in the static bench tests simulate the dynamic ones in character and size; the difference is that here they are applied in static mode with stresses measurement.

Based on the fact that for each point of the structure at any time $t$ (more precisely peak moment), the stress is determined by the vertical and horizontal forces applied in the considered places (right or left side beams - with indices 1 and 2), it is obtained:

- for vertical forces $\mathrm{F}_{\mathrm{z} 1}$ and $\mathrm{F}_{\mathrm{z} 2}$ :

$$
F_{z 1}(t)=F_{z s}+F_{z q}(t) F_{z 2}(t)=F_{z s}+F_{z q}(t)+F_{z d}(t)
$$

or taking into account only the peak (amplitude) values $F_{z q}$ and $\mathrm{F}_{\mathrm{zd}}$, according to (4) and (5) we get:

$$
\begin{gathered}
F_{z 1}(t)=F_{z s}(1 \pm \alpha \pm \beta) F_{z 2}(t)=F_{z s}(1 \pm \alpha \pm \beta) \\
\text { - for horizontal loads } \\
F_{y 1}= \pm F_{y q} \pm F_{y d 1} F_{y 2}= \pm F_{y q 2} \pm F_{y d 2}
\end{gathered}
$$

or in the case of an even distribution between the two side beams, i. for $\mathrm{F}_{\mathrm{y} 1}=\mathrm{F}_{\mathrm{y} 2}=\mathrm{F}_{\mathrm{y}}$ and taking into account, according to (6), the equality between the amplitude values of the quasi-static and dynamic components (ie $\mathrm{F}_{\mathrm{yq}}$ and $\mathrm{F}_{\mathrm{yd}}$ ), 
the maximum and minimum values of the total horizontal force of the bogie are obtained, for the tense state

$$
\max / \min 2 F_{y}= \pm 0,5\left(F_{z S}+0,5 \cdot m^{+} \cdot g\right)
$$

When the bogie is loaded with different combinations between the vertical forces $\mathrm{F}_{\mathrm{z} 1}$ and $\mathrm{F}_{\mathrm{z} 2}$ taken from formula (8) and the horizontal force from (10), code. UIC-515 and EN 13749 [7] prescribe mandatory 9 combinations of loads, shown in Table 1 and with the corresponding values for the tested bogie, confirmed by [4].

From these combinations, the stresses from two of them must be taken, namely the largest and the smallest values for each point of the structure, which represent the simulated maximum $\sigma_{\max }$ and minimum $\sigma_{\min }$ stresses at these loads; when plotting them in the Goodman diagram on the ordinate, for abscissas $\sigma_{m}=\left(\sigma_{\max }+\sigma_{\min }\right) / 2$, the obtained points must be inscribed in its contours.

Table 1. Load combinations for static bench test of passenger bogie at operating loads

\begin{tabular}{|c|c|c|c|}
\hline \multirow{2}{*}{$\begin{array}{l}\text { Combi- } \\
\text { nation } \\
\text { № }\end{array}$} & \multicolumn{2}{|c|}{ Vertical loads } & \multirow{2}{*}{$\begin{array}{c}\text { Horizontal } \\
\text { transverse load } \\
\mathrm{F}_{\mathrm{y}}\end{array}$} \\
\hline & $F_{z 1}$ & $\mathrm{~F}_{\mathrm{z} 2}$ & \\
\hline 1. & $\mathrm{~F}_{\mathrm{zs}}$ & $\mathrm{F}_{\mathrm{zs}}$ & 0 \\
\hline 2. & $\mathrm{~F}_{\mathrm{zs}}(1+\alpha-\beta)$ & $\mathrm{F}_{\mathrm{zS}}(1-\alpha-\beta)$ & 0 \\
\hline 3. & $\mathrm{~F}_{\mathrm{zs}}(1+\alpha-\beta)$ & $\mathrm{F}_{\mathrm{zs}}(1-\alpha-\beta)$ & $+2 \mathrm{~F}_{\mathrm{y}}$ \\
\hline 4. & $\mathrm{~F}_{\mathrm{zs}}(1+\alpha+\beta)$ & $\mathrm{F}_{\mathrm{zS}}(1-\alpha+\beta)$ & 0 \\
\hline 5. & $\mathrm{~F}_{\mathrm{zs}}(1+\alpha+\beta)$ & $\mathrm{F}_{\mathrm{zs}}(1-\alpha+\beta)$ & $+2 F_{y}$ \\
\hline 6. & $\mathrm{~F}_{\mathrm{zs}}(1-\alpha-\beta)$ & $\mathrm{F}_{\mathrm{zs}}(1+\alpha-\beta)$ & 0 \\
\hline 7. & $\mathrm{~F}_{\mathrm{zs}}(1-\alpha-\beta)$ & $\mathrm{F}_{\mathrm{zs}}(1+\alpha-\beta)$ & $-2 F_{y}$ \\
\hline 8. & $\mathrm{~F}_{\mathrm{zs}}(1-\alpha+\beta)$ & $\mathrm{F}_{\mathrm{zs}}(1+\alpha+\beta)$ & 0 \\
\hline 9. & $\mathrm{~F}_{\mathrm{zs}}(1-\alpha+\beta)$ & $\mathrm{F}_{\mathrm{zs}}(1+\alpha+\beta)$ & $-2 F_{y}$ \\
\hline
\end{tabular}

It is recommended that the loads in combinations №№ 3, 5, 7, and 9 (Table 1) be repeated because they are extreme and most likely are the stressess generated by them. The above method is known as the "operating load method".

A static bench test is prescribed by the method of extreme loads, which is applied with a single static load at higher values of vertical and horizontal forces respectively $\mathrm{F}_{\mathrm{z} 1 \max }, \mathrm{F}_{\mathrm{z} 2 \max }, 2 \mathrm{~F}_{\mathrm{ymax}}$ - determined by the formulas:

$$
\begin{gathered}
F_{z 1 \text { max }}=F_{z 2 \max }=\left(m_{V C E}-2 m^{+}\right) \cdot g \\
m_{V C E}=\left(m_{V O M}+2 \cdot n \cdot 80\right) \\
2 F_{y \max }=2 \cdot\left(10+m_{V C E}\right), k N
\end{gathered}
$$

where: $m_{V C E}$ is the gross mass of the wagon under extreme load; $m_{V O M}$ - the own weight (tare) of the wagon; $m^{+}$mass of the bogie; $n$ - the number of seats in the car; $F_{z 1 \max }$ and $2 F_{z 2 \max }-$ maximum (exclusive) vertical forces applied to the right resp. left side beams; $2 F_{\text {ymax }}$ - maximum (exclusive) horizontal effort of the bogie.

The conditions for admissibility in the test with extreme loads are: 1) the stresses at any point of the structure do not exceed the limit of proportionality of the material; 2) no residual deformations in the structure after its release from the loads.

\section{CALCULATION OF BASIC LOAD-BEARING ELEMENTS OF A PASSENGER BOGIE OPERATED BY BDZ PASSENGER TRANSPORT EOOD}

The calculation of the bogies is realized through an engineering package of software products. The bogies are 3D modeled in the middle of Soidworks in accordance with their original design documentation, and the welds are created in a uniform shape by the existing modeler in the computer system (CAD). The models thus created are statically loaded by the extreme forces defined above in accordance with UIC-515 and EN 13749, using the finite element method (FEA). For this purpose, the models are divided into elements with dimensions from 2 to $4.4 \mathrm{~mm}$, which makes a compromise decision in order to obtain a numerical solution within a reasonable time interval. At the same time, the sensitivity of the numerical process to the existing stress concentrations in the welded joints is limited, and admissible imperfections in the welded seam are not taken into account $[26,27]$. Results were obtained for the stress state and for the deformations of the calculated elements.

6.1. Calculation of main load-bearing elements of Görlitz $\mathrm{Va} / \mathrm{DVJ}$ type bogie

For the construction of a Görlitz Va/DVJ passenger bogie, the load values for the different combinations are given in Table 2.

Table 2. Load combinations for static bench test of passenger bogie type Görlitz Va/DVJ at operating loads (at accepted $\alpha=0.15$ and $\beta=0.3$ for poor road condition)

\begin{tabular}{|c|c|c|c|}
\hline \multirow{2}{*}{$\begin{array}{l}\text { Combi- } \\
\text { nation } \\
\text { № }\end{array}$} & \multicolumn{2}{|c|}{ Vertical loads } & $\begin{array}{c}\text { Horizontal transverse } \\
\text { load }\end{array}$ \\
\cline { 2 - 4 } & $\mathrm{F}_{\mathrm{z} 1}$ & $\mathrm{~F}_{\mathrm{z} 2}$ & $2 \mathrm{~F}_{\mathrm{y}}$ \\
\hline 1. & 88,275 & 88,275 & 0 \\
\hline 2. & 75,034 & 48,551 & 0 \\
\hline 3. & 75,034 & 48,551 & 59,105 \\
\hline 4. & 127,999 & 101,517 & 0 \\
\hline 5. & 127,999 & 101,517 & 59,105 \\
\hline 6. & 48,551 & 75,034 & 0 \\
\hline 7. & 48,551 & 75,034 & $-59,105$ \\
\hline 8. & 101,517 & 127,999 & 0 \\
\hline 9. & 101,517 & 127,999 & $-59,105$ \\
\hline
\end{tabular}

The generalized scheme of the forces on the frame of the bogie type Görlitz $\mathrm{Va} / \mathrm{DVJ}$, applied from the side of the carbody is given in Fig.9.

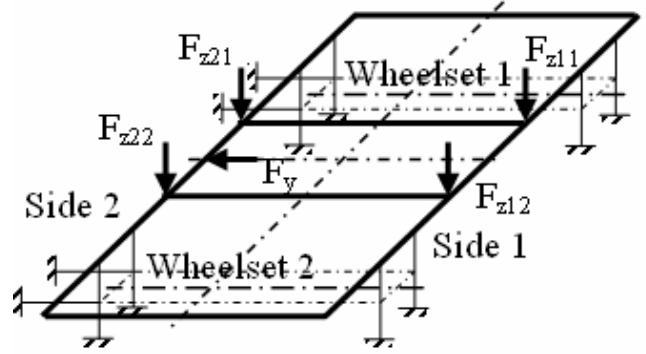

Figure 9. Loads of bogie type Görlitz Va/DVJ.

The vertical load is transmitted in the supports of the suspension from the SS and $\mathrm{F}_{\mathrm{z} 11}=\mathrm{F}_{\mathrm{z} 12}=\mathrm{F}_{\mathrm{z} 1} / 2$, and the horizontal-transverse load is in the support between a page of the frame and the overhang beam.

The maximum values for determining the stresses in the structure of the frame of the considered passenger bogie are in combination № 5 .

The values of the loads are: $\mathrm{F}_{\mathrm{z} 11}=\mathrm{F}_{\mathrm{z} 12}=\mathrm{F}_{\mathrm{z1}} / 2=64 \mathrm{kN}$; $\mathrm{F}_{\mathrm{z} 21}=\mathrm{F}_{\mathrm{z} 22}=\mathrm{F}_{\mathrm{z} 2} / 2=50.76 \mathrm{kN}$ and $\mathrm{F}_{\mathrm{y}}=29.55 \mathrm{kN}$ shown in figure 6.

The results of the SolidWorks program in the calculation of the bogie frame type Görlitz $\mathrm{Va} / \mathrm{DVJ}$ are given in Table 3. 
Table 3. Study Results for bogie frame type Görlitz $\mathrm{Va} / \mathrm{DVJ}$

\begin{tabular}{|l|l|l|l|}
\hline Name & \multicolumn{1}{l}{ Type } & \multicolumn{1}{l|}{ Max } & Location \\
\hline Stress1 & VON: von & $66,87 \mathrm{MPa}$ & $(0 \mathrm{~mm}, 152 \mathrm{~mm}$, \\
& Mises Stress & Node: 43 & $-924.8 \mathrm{~mm})$ \\
\hline Displa- & URES: & $0.388 \mathrm{~mm}$ & $(6.4373 \mathrm{e}-006 \mathrm{~mm}$, \\
cement1 & Resultant & Node: & $190 \mathrm{~mm}$, \\
& Displacement & 11330 & $-878 \mathrm{~mm})$ \\
\hline Strain1 & ESTRN: & 0.000194 & $(-877.625 \mathrm{~mm}$, \\
& Equivalent & Element: & $-4 \mathrm{~mm}$, \\
& Strain & 9439 & $-1052.94 \mathrm{~mm})$ \\
\hline
\end{tabular}

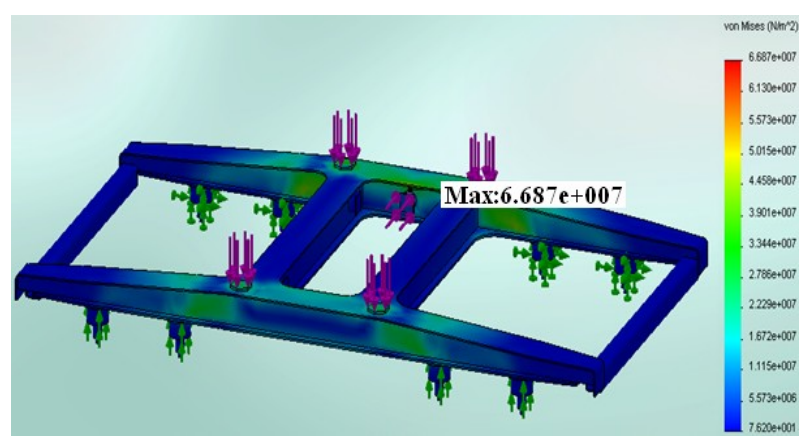

Figure 10. Stress condition of the bogie frame type Görlitz $\mathrm{Va} / \mathrm{DVJ}$

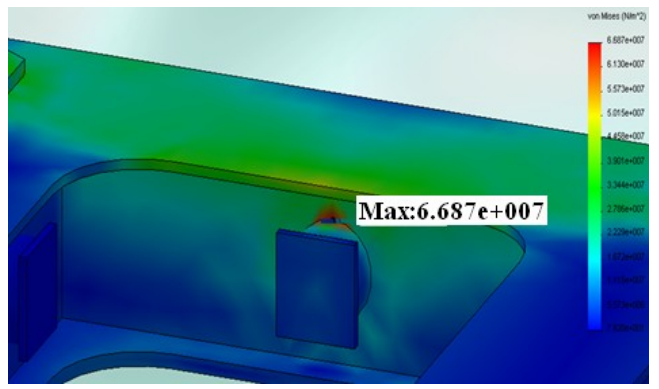

Figure 11. Stress state with maximum value.

In figure 10 shows the stress state of the bogieframe, the maximum value being $66.87 \mathrm{MPa}$ obtained in the middle of the beam in the area of the weld of the lateral bump (Fig. 11). In other areas, maxima have been reported, which are $15-30 \%$ lower stresses values.

The displacements shown in the table are within normal limits, in accordance with the regulations.

\subsection{Calculation of main load-bearing elements of GP200} type bogie

For the construction of a GP200 passenger bogie, the load values for the different combinations are given in Table 4.

The generalized scheme of the loads on the frame of the bogie type GP200, applied from the side of the carbody is given in fig. 12 .

The vertical load is transmitted in the supports of the suspension from the SS and $\mathrm{F}_{\mathrm{z} 11}=\mathrm{F}_{\mathrm{z} 12}=\mathrm{F}_{\mathrm{z} 1} / 2$, and the horizontal-transverse load is in the support between a pageof the frame and the overhang beam.

The maximum values for determining the stresses in the structure of the frame of the considered passenger bogie are in combination № 5 .

The values of the loads are: $F_{z 11}=F_{z 12}=F_{z 1} / 2=$ $71,12 \mathrm{kN} ; \mathrm{F}_{\mathrm{z} 21}=\mathrm{F}_{\mathrm{z} 22}=\mathrm{F}_{\mathrm{z} 2} / 2=56,41 \mathrm{kN}$ and $\mathrm{F}_{\mathrm{y}}=31,39 \mathrm{kN}$ shown in figure 12 .
Table 4. Load combinations for static bench test of passenger bogie type GP200 at operating loads (at accepted $\alpha=0.15$ and $\beta=0.3$ for poor road condition)

\begin{tabular}{|c|c|c|c|}
\hline \multirow{2}{*}{$\begin{array}{l}\text { Combi- } \\
\text { nation } \\
\text { № }\end{array}$} & \multicolumn{2}{|c|}{ Vertical loads } & $\begin{array}{c}\text { Horizontal transverse } \\
\text { load }\end{array}$ \\
\cline { 2 - 4 } & $\mathrm{F}_{\mathrm{z} 1}$ & $\mathrm{~F}_{\mathrm{z} 2}$ & $2 \mathrm{~F}_{\mathrm{y}}$ \\
\hline 1. & 98,1 & 98,1 & 0 \\
\hline 2. & 83,385 & 53,955 & 0 \\
\hline 3. & 83,385 & 53,955 & 62,784 \\
\hline 4. & 142,245 & 112,815 & 0 \\
\hline 5. & 142,245 & 112,815 & 62,784 \\
\hline 6. & 53,955 & 83,385 & 0 \\
\hline 7. & 53,955 & 83,385 & $-62,784$ \\
\hline 8. & 112,815 & 142,245 & 0 \\
\hline 9. & 112,815 & 142,245 & $-62,784$ \\
\hline
\end{tabular}

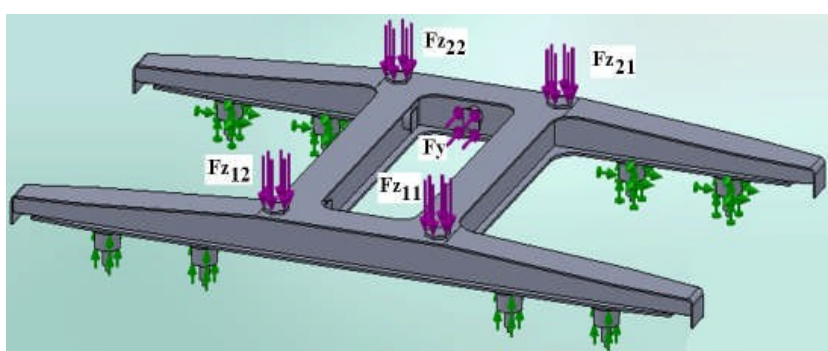

Figure 12. Load and supports for bogie type GP200.

The results of the SolidWorks program in the calculation of the bogie frame type GP200 are given in Table 5.

In figure 13 shows the stress state of the bogie frame, the maximum value being $72.39 \mathrm{MPa}$ obtained in the middle of the beam in the area of the weld of the lateral bump. In other areas, maxima have been reported, which are $10-30 \%$ lower stresses values.

Table 5. Study Results for bogie frame type GP200

\begin{tabular}{|c|c|c|c|}
\hline Name & Type & Max & Location \\
\hline Stress1 & $\begin{array}{l}\text { VON: von } \\
\text { Mises Stress }\end{array}$ & $\begin{array}{l}72.39 \mathrm{MPa} \\
\text { Node: } 43\end{array}$ & $\begin{array}{l}(0 \mathrm{~mm}, 152 \mathrm{~mm}, \\
-924.8 \mathrm{~mm})\end{array}$ \\
\hline $\begin{array}{l}\text { Displa- } \\
\text { cement1 }\end{array}$ & $\begin{array}{l}\text { URES: } \\
\text { Resultant } \\
\text { Displacement }\end{array}$ & $\begin{array}{l}0.5612 \mathrm{~mm} \\
\text { Node: } 11330\end{array}$ & $\begin{array}{l}(6.4373 \mathrm{e}-006 \mathrm{~mm}, \\
190 \mathrm{~mm}, \\
-878 \mathrm{~mm})\end{array}$ \\
\hline Strain1 & $\begin{array}{l}\text { ESTRN: } \\
\text { Equivalent } \\
\text { Strain }\end{array}$ & $\begin{array}{l}0.000229 \\
\text { Element: } \\
9439\end{array}$ & $\begin{array}{l}(-877.625 \mathrm{~mm}, \\
-4 \mathrm{~mm}, \\
-1052.94 \mathrm{~mm})\end{array}$ \\
\hline
\end{tabular}

The displacements shown in the table are within normal limits, in accordance with the regulations.

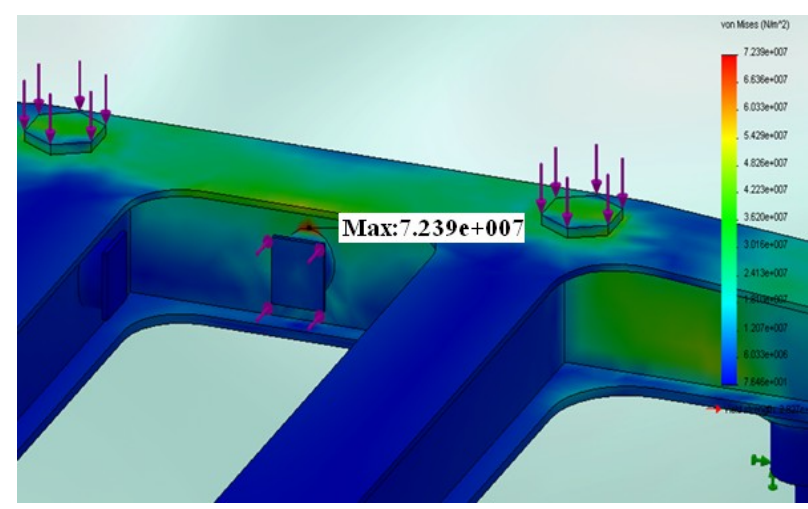

Figure 13. Stress state with maximum value.

In total for both bogies it can be concluded that the maximum stresses are in the area of the bumper, assuming that the reason is in the prevailing local stresses of pressure from the lateral forces $\mathrm{F}_{\mathrm{y}}$. The maximum stresses are in the 
$\mathrm{T}$ weld of the bumpers, and the formation of tired micro cracks in tests confirms this.

6.3. Goodman diagram for Görlitz Va/DVJ and GP200 passenger bogies frame

Drawing the theoretically and experimentally obtained Goodman diagram, we determine the position of the endangered stresses for the sections of the frames of the two bogies.

For passenger bogie type Gorlitz Va/DVJ:

$\sigma_{\mathrm{m}}=66,87 \mathrm{MPa}$ and $\sigma_{\max }=80,244 \mathrm{MPa}$;

For passenger bogie type GP200:

$\sigma_{\mathrm{m}}=72,39 \mathrm{MPa}$ and $\sigma_{\max }=86,868 \mathrm{MPa}$.

The obtained values plotted in the Goodman diagram are shown in Fig.14.

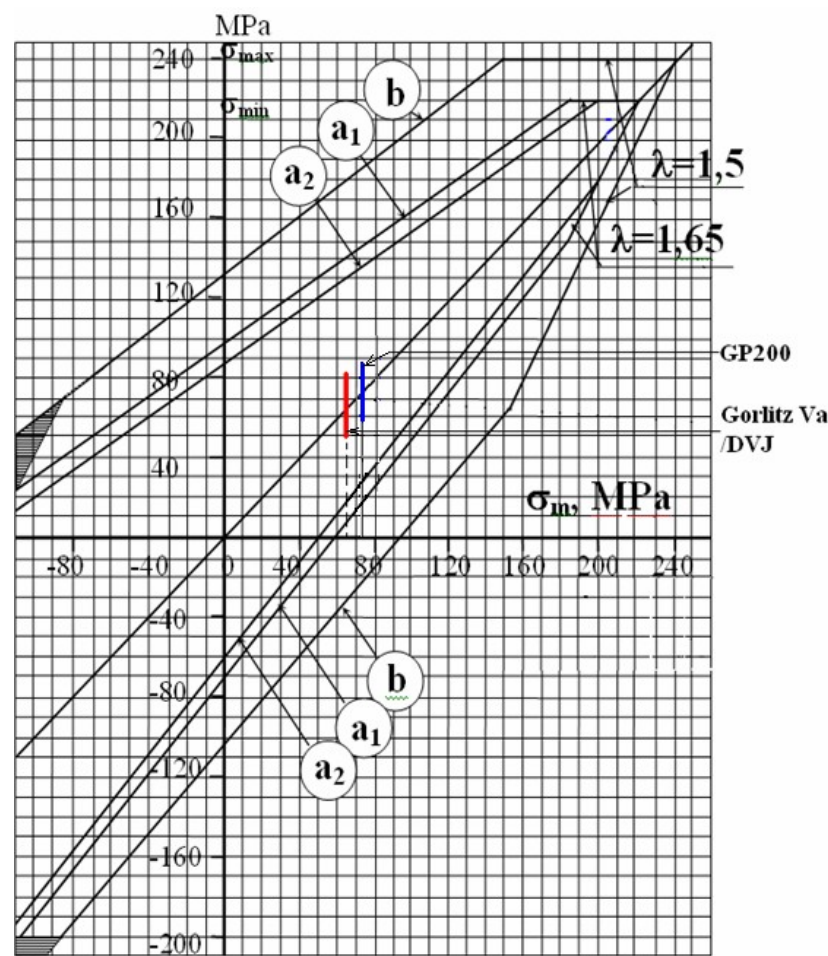

Figure 14. Goodman diagram with plotted stresses values.

The values of stresses for the frame of passenger bogies type Görlitz Va/DVJ and GP200 are in the outline $\mathrm{a}_{2}$, which gives grounds for the necessary strength of the structure, but we still recommend strict control of welds and determining the coefficient of accumulation of damage $[4,28]$.

\section{CONCLUSION}

In the present article the constructions of passenger carriages in operation of BDZ "Passenger Transport" EOOD are considered. Cases of failures that are related to mass defects and are mainly due to design deficiencies and mass deviations from technological requirements are analyzed. Particular attention is paid to the problems in the construction of passenger carriages type YT-72, Görlitz$\mathrm{V} / \mathrm{Va} / \mathrm{DVJ}$ and GP 200. The weak points in the constructions of the indicated bogies and the conditions for the occurrence of cracks have been determined. The article examines the strength of the frames of the specified passenger bogies. The loads are in accordance with the requirements of UIC-515 and EN 13749. The various fatigue strength tests of the passenger bogie are indicated. It is calculated that the construction of the frame has the necessary fatigue strength, but nevertheless it is recommended to strictly control the welds and determine the coefficient of accumulation of damage.

\section{REFERENCES}

[1] Petrovic D., Rakanovic R., Zeleznicka vozila Praktikum., Kraljevo, (2006)

[2] Petrovic D., Aleksandrov V., Jeleznicka vozila.Osnove, MF Kraljevo, ISBN 978-86-82631-66-8 p.223, (2013)

[3] Penchev Ts., Atmadzhova D. Issues from operation, repair and recycling of passenger cars from the park of BDZ, VTU "T. Kableshkov", Sofia, (2003)

[4] Penchev Ts., Atmadzhova D. Strength and durability of automobile and railway technology, VTU, "T. Kableshkov", Sofia, (2007).

[5] Nikolov V., MODELLING AND STRENGT ANALYSIS OF THE WHEELSETS OF LOCOMOTIVES OF TYPE 86, Scientific Journal "Mechanics of Transport Communications" Volume 16 , Issue 3/3, No 1678pp.VI-48 - VI-53, ISSN 1312 3823, (2018)

[6] Nikolov V., Reliability indicators of the brake distributors KE 1 for rolling stock in operation, IX International Conference "Heavy Machinery-HM 2017”, Zlatibor, (2017)

[7] NIKOLOV V., MODELING AND STRENGTH ANALYSIS OF THE AXLES OF BOGIE WITH VARIABLE-GAUGE WHEELSETS, The Fourth International Symposium for Students CPMA 2015, (2015)

[8] UIC 515-4, PASSENGER ROLLING STOCK TRAILER BOGIES - RUNNING GEAR - BOGIE RUNNING GEAR - BOGIE FRAME STRUCTURE STRENGTH TESTS, (1993)

[9] Ivanov A.I, Structural Dynamics. publ. "Avangard Prima”, ISBN 978-954-323-684-8, Sofia, (2010).

[10] EN 13749:2011 - Railway applications. Wheelsets and bogies. Method of specifying the structural requirements of bogie frames, (2021)

[11] EN 14363:2016 Railway applications - Testing for the acceptance of running characteristics of railway vehicles - Testing of running behaviour and stationary tests, June, (2016).

[12] EN 15827:2011 Railway applications - Requirements for bogies and running gears, Brussels: EUROPEAN COMMITTEE FOR STANDARDIZATION, (2011)

[13] UIC 510-3, WAGONS - STRENGTH TESTING OF 2 AND 3-AXLE BOGIES ON TEST RIG, International Union of Railways (UIC), (1989)

[14] UIC 615-4, "Movie power units bogies and running gear bogie frame structure strength tests,", International Union of Railway, (1994)

[15] UIC 515-4 (E), 1st Edition, January 1, 1993 PASSENGER ROLLING STOCK - TRAILER 
BOGIES - RUNNING GEAR - BOGIE RUNNING GEAR - BOGIE FRAME STRUCTURE STRENGTH TESTS, (1993)

[16] Technical specification for interoperability of the rolling stock - freight wagons subsystem of the transEuropean conventional rail system, (2006)

[17] ERRI B12/RP17-8th Edition, Programme of tests to be carried out on wagons with steel underframe and body structure (suitable for being fitted with the automatic buffing and draw coupler) and on their cast steel frame bogies, Utrecht, April, (1997)

[18] ERRI B 12/RP 60, 2nd Edition, regulation for proof tests and maximum permissible stresses, Utrecht, (1998).

[19] EN 12663-1:2010 Railway applications - Structural requirements of railway vehicle bodies - Part 1: Locomotives and passenger rolling stock (and alternative method for freight wagons), (2010).

[20] DVS 1612:2014 Design and endurance strength analysis of steel welded joints in rail-vehicle construction, (2014)

[21] Eurocode 3: Design of steel structures - (2005)

[22] Svetoslav SLAVCHEV, Vladislav MAZNICHKI, Valeri STOILOV, Stanislav ENEV, Sanel PURGIC. METHODOLOGY FOR THE EVALUATION OF MATERIAL FATIGUE IN THE AREA OF WELDED SEAMS OF RAILWAY BOGIES ON THEORY WAY. Materials Science and Engineering, VOL. 618 ISSN: 1757-899X, (2019)

[23] P. Štastniak, M. Moravčík, P. Baran и L. Smetanka, „Computer aided structural analysis of newly developed railway bogie frame," MATEC Web of Conferences, том 157, № 157, (2018).

[24] Н. Dannbauer, С. Gaier и K. Hofwimmer, „Fatigue Analysis of Welding Seams and Spot Joints in Automotive Structures", ARABIAN JOURNAL FOR SCIENCE AND ENGINEERING, (2005).

[25] Atmadzhova D., Determining the strength of elements of passenger carriage type Y32, International
Scientific Forum "Engineering and Construction Technologies in Transport - 2014" Banya, Razlog, September 18-19, 2014, Article 1046, vol. 12, issue 3/3, pp VI-1-VI-10, (2014)

[26] Kolarov I. Concentration in welding joints due to the presence of pores in the seam. Scientific Journal "Mechanics of Transport Communications", Volume 18, Issue 3/1, XIII-21 - 26, ISSN 1312-3823, (2020)

[27] Kolarov I. Stress state in a weld with a linear and point concentrator. Scientific Journal "Mechanics of Transport Communications" Volume 18, Issue 3/1, XIII - 14 - 19, ISSN 1312-3823, (2020)

[28] Jankovic Miodrag D., Malociklusni zamor, Msinski Fakultet, Beograd, (2001).

\section{Analiza grešaka putničkih obrtnih postolja vagona iz železničkog sistema Republike Bugarske}

\author{
Vanio Ralev ${ }^{1 *}$, Dobrinka Atmadžova ${ }^{1}$ \\ ${ }^{1}$ Mašine i građevinske tehnologije u \\ transportu/transportnoj opremi, Univerzitet za saobraćaj \\ Todor Kableškov, Sofija (Bugarska) \\ Ovaj rad je zasnovan na pregledu studije oštećenja \\ putničkih obrtnih postolja na železničkim vozilima. \\ Analiziraju se rezultati istraživanja pouzdanosti putničkih \\ obrtnih postolja iz parka Bugarske državne železnice \\ (BDŽ). Predstavljene su konstrukcije putničkih obrtnih \\ postolja tipa ljuljaške u eksploataciji Republike Bugarske - \\ IT72, Gorlitz V i GP200. Naznačeni su najčešći kvarovi \\ putničkih obrtnih postolja. Uspešno su identifikovani opšti \\ kvarovi, verovatni uzroci kvarova $i$ načini za njihovo \\ minimiziranje.
}

Ključne reči: Železnička vozila, Putnička kola, Obrtna postolja. 